\title{
BREAST CANCER SCREENING AMONG BRAZILIAN WOMEN: AN INTEGRATIVE REVIEW
}

Mônica O. B. Oriá1, Camila T. M. Vasconcelos¹, Marli T. G. Galvão', Aubrey L. Doede², Dan Wilson², Reanna Panagides², Emma M. Mitchell ${ }^{2}$

${ }^{1}$ Universidade Federal do Ceará - Fortaleza (CE), Brazil.

¿University of Virginia - Charlottesville (VA), EUA.

Objectives: The aim of this integrative literature review was to explore empirical literature surrounding breast cancer screening practice among Brazilian women. Methodology: OVID Medline, CINAHL, Lilacs, Scopus and Web of Science/ SciELO were used to identify articles in English, Portuguese and Spanish languages. Twenty eight original articles were included using inclusion and exclusion criteria. Results: Most of the studies were developed in the Southeast $(\mathrm{n}=14)$ and South ( $\mathrm{n}=7$ ). No studies were found involving populations from North Brazil. The most studies enrolled populations from exclusively urban areas $(\mathrm{n}=21)$. Of the total of 91,207 women involved in the 28 studies, 15,801 never had mammograms and 48,944 had mammograms in their lifetime; 555 had never undergone breast clinical examination, and 8,114 had done it at least once in their lives. To screen breast cancer the studies used mammograms ( $\mathrm{n}=21$ ), breast clinical examination $(\mathrm{n}=11)$ and mobile mammograms $(\mathrm{n}=1)$. White women, with higher schooling, better socioeconomic status have access to better ways of breast cancer screening. Conclusion: The gaps in breast cancer screening are related to social and racial inequities and problems about spatial distribution of specialized equipment resources and professional. 